\title{
Factors That Influence Domestic Violence Practice Self-Efficacy: Implications for Social Work
}

\author{
Fran Danis
}

\begin{abstract}
This article discusses the results of an exploratory study to identify facilitating factors and barriers for practice self-efficacy with battered women. Based on self-efficacy theory, personal factors such as professional experience, academic preparation, personal experience, and continuing education training wereexplored with a random sample of licensed and degreed professional social workers.

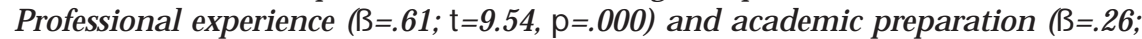
$t=4.29, p=000$ ) were the strongest predictors of self-efficacy. These findings suggest that to advancethecapacity of social workers to respond to domestic violence, social work education, practitioners, and researchers have a number of important steps available to take.
\end{abstract}

Keywords: Domestic violence, self-efficacy, social work practice, domestic abuse

$O^{\prime}$ urviving an abusive relationship can be a complicated process that has an impact on all facets of a person's life, including relationships with children, Family, friends, neighbors, and employers. It may mean getting help from unfamiliar and complicated systems such as criminal and civil courts, law enforcement, legal services, social services, hospitals, employment, and housing services. The most difficult part of surviving may be finding someone with the knowledge and skills to effectively help negotiate the myriad of decisions needed to be made, emotions to sort through, and options to consider. Although we know that thousands of women are faced with this potentially lethal, complicated, and emotionally overwhelming problem every day, what we do not know is the capacity of professional social workers to assist battered women when they reach out for assistance.

This article presents the results of an exploratory study to identify facilitating factors and barriers for competent service provision to battered women. Based on self-efficacy theory (Bandura, 1986; 1997), personal factors such as professional experience, academic preparation, continuing education, and personal experience were explored. The implications for social work education, practice, and research are addressed.

Fran Danis is Assistant Professor at the School of Social Work, University of Missouri, Columbia, MO 65211.

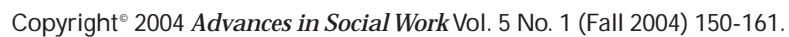

Indiana University School of Social Work. 


\section{SOCIAL WORK RESPONSE TO DOMESTIC VOLENCE}

Domestic violence is a multifaceted problem that is defined as a pattern of coercive behaviors that involve physical abuse or the threat of physical abuse and may include repeated psychological abuse, sexual assault, progressive social isolation, deprivation, intimidation, or economic coercion. Domestic violence refers to violence perpetrated by adults or adolescents against their intimate partners in current or former dating, married, or cohabitating relationships of heterosexuals, gay men, lesbians, bisexuals, or transgendered people. Domestic violence is one type of "family violence," a term that refers to all types of violence that occurs within a family, including violence towards adult partners, children, siblings, parents, and elders (Salber \& Taliaferro, 1995). Domestic violence is also one type of "violence against women," a broad term that includes sexual assault, stalking, female genital mutilation, sexual harassment, and violence within intimate relationships. The terms domestic violence, domestic abuse, spouse abuse, woman abuse, and wife battering are often used interchangeably. Since the late 1970s, women who have been victims of abuse by their male intimate partners have been referred to as "battered women" (Walker, 1979).

In the vast majority of cases, domestic violence is committed by a man against his female partner. The National Violence Against Women Survey (Tjaden \& Thoennes, 1998) estimates 5.9 million incidents of physical assaults against women annually, with approximately $76 \%$ of those incidents perpetrated by current or former husbands, cohabiting partners, or dates. Fourteen to $50 \%$ of all women will experience domestic violence by a male partner at least once in their lifetime (Straus, Gelles \& Steinmetz, 1980). Nearly one in three of all female homicide victims were killed by their husbands, former husbands, or boyfriends. In contrast, just over 3\% of male homicide victims are killed by their wives, former wives, or girlfriends (Bachman \& Saltzman, 1995). Two studies conducted by the Centers for Disease Control (CDC) found that more than one-third of American adults have witnessed a man beating a female spouse or partner and $50 \%$ of all emergency room visits by injured women were the result of a partner's abuse (Rand, 1997).

The links between domestic violence and the use of public assistance (Raphael \& Tolman, 1997), co-occurrence with child abuse (Edleson, 1999), substance abuse (Bennett, 1995), and prevalence among populations of homeless women (Browne \& Bassuk, 1997) have been established. These prevalence studies establish domestic violence as a crosscutting issue with a high probability that professional social workers will encounter persons experiencing domestic violence in their caseloads. What is unknown is how social workers respond to survivors and victims of abuse.

Previous research looking at the beliefs and practices of service providers confirmed that many held stereotypical views about domestic abuse and battered women viewed abuse within the context of the interaction between family members, thereby, blaming the victim and placed primary importance on keeping the family together for the sake of the children. Through interviews, surveys, and reviews of case records, researchers found that social workers viewed violence as 
their client's masochistic tendencies (Ball, 1977), blamed the victim (Dobash \& Dobash, 1979; Davis \& Carlson, 1981), failed to recognize abuse as a problem (Bowker, 1983; Hansen, Harway \& Cervantes, 1991; Pagelow, 1981; Eisikovits \& Buchbinder, 1996), and failed to make appropriate interventions and referrals (Bass \& Rice, 1979; Davis, 1984; Ross \& Glisson, 1991).

What could account for this history of bias and blame? What factors determine social work response to domestic violence? Davis and Carlson (1981) surveyed frontline workers in organizations likely to provide services to battered women in a three county moderate-sized metropolitan area. As compared to other service providers, family service workers tended to adopt victim-blaming attitudes. In a follow-up analysis, Davis (1984) looked at the factors that different groups of service providers believe impede an abused wife and her abusing husband from preventing subsequent acts of violence as well as service providers' recommendations for actions each party should take. Among Davis' findings were that professional experience, personal experience, and training were all positively correlated with each other, leading Davis to conclude that knowledge increases exposure and vice versa. Those with high levels of training were far more likely to have had high levels of professional experience. Training also led respondents to identify lack of services as a barrier to the wife's seeking change.

Davis and Carlson (1986) next looked at public school personnel, including school social workers. Findings from this study confirmed that the more professional and personal experience with domestic violence, the more knowledge of the subject. Tilden, Schmidt, Limandri, Chiodo, Garland and Loveless (1994) also found that the level of professional experience with domestic violence makes a difference in how social workers respond to battered women.

Although these findings date back to the 1970s, there are few published studies that address social work response to domestic violence in recent years. These dated studies also had a number of other limitations. They all used convenience samples of persons employed in social service agencies and made an assumption that persons employed by those agencies were professionals with an educational degree in social work. Earlier studies also failed to identify a theoretical framework that connects the various independent factors with the desired outcomes or dependent variables. For example: what is the mechanism that links the factors of education or past personal experience with domestic violence and translates them into the ability to respond to cases of domestic violence?

\section{DOMESTIC VOLENCE PRACTICE SELF-EFFICACY}

This study used self-efficacy theory to develop the linkage between personal factors influencing the capacity and response of social workers to domestic violence. Self-efficacy "is the extent to which people believe they are capable of exercising influence and control over the events that effect their lives" (Bandura, 1994, p. 421). It is not just the skills that people have, but their judgment of what they can do with whatever skills they possess (Bandura, 1986).

Self-efficacy theory has been applied extensively to the training and development of helping professionals including social workers, psychologists, nurses, 
and physicians. Within social work, the theory has been applied and tested within the context of hospital social work practice (Holden, Cuzzi, Spitzer, Rutter, Rosenburg \& Chernack, 1996), teaching research skills to social work students (Holden, Barker, Meenaghan \& Rosenberg, 1999), and teaching generalist social work skills (Holden, Meenaghan \& Metrey, 2002). Self-efficacy has been found to predict subsequent behavioral outcomes (Holden, 1991; Abusabha \& Achterberg, 1997), thus creating the link between perceived self-efficacy and the behavioral response.

Self-efficacy is context specific. For example, someone who works in child welfare may have high self-efficacy for working with children but low self-efficacy for assisting in end of life decision making for an elderly individual. Therefore, a global measure of self-efficacy cannot be applied to specific contexts. As this study is the first to apply self-efficacy theory in this specific domain, it was necessary to create the concept of domestic violence practice self-efficacy. Domestic violence practice self-efficacy was defined as the extent to which social workers believe they are capable of assisting battered women.

The research question guiding this study was what are the personal factors that facilitate or act as barriers to domestic violence practice self-efficacy? Based on prior literature, it was hypothesized that each of these factors: social work education, continuing education, professional experience, and personal experience would be positively associated with self-efficacy in this domain. Higher levels of each variable would result in higher levels of self-efficacy.

\section{METHODOLOGY}

A written survey was developed and pilot tested for content validity on 10 social work practitioners employed by a community-based domestic violence agency and work directly with battered women. Staff at a national organization that provides training and consultation on domestic violence also reviewed the survey. It was mailed to a random sample of 1,000 licensed social workers licensed by a large southwestern state's Board of Social Work Examiners. The SPSS random sampling function was used to draw a pure random sample. Resources limited follow-up to the survey to one reminder postcard and no financial or material incentives were available to help boost return rates.

The instrument used the definition of domestic violence outlined previously. The instrument contained a five point Likert-like scale ( $1=$ not at all to $5=$ a great deal) with questions relating to personal factors such as to what extent respondents had professional experience working with battered women and to what extent have you or members of your family been personally affected by domestic violence. In addition to asking for the highest social work degree completed, respondents were asked three questions that focused on social work education. These questions served as a substitute measure for knowledge of domestic violence and addressed the extent of specific coursework on domestic violence identification, assessment, and intervention; whether field placement experiences prepared them for working with battered women; and the overall extent that their formal social work education (both classroom and field) prepared them for working with battered women. To measure the impact of continuing education on self- 
efficacy, respondents were asked, "How many hours of continuing education or in-service training on domestic violence have you received in the past two years?" Forced choice response categories include: 1) none, 2) 3 hours or less, 3) 4 to 8 hours, 4) 9 to 16 hours, and 5) 17 or more hours. These response groupings were chosen as they represent the length of standard conference sessions or continuing education workshops.

The survey measured domestic violence practice self-efficacy through an 11item scale that has a reliability coefficient of .95. The scale contained questions on comfort and perceived capability level in identifying and discussing domestic violence with clients, assessing the level of danger the client is facing, and helping clients with safety planning and other interventions.

The mean of the self-efficacy scale was used to create a "self-efficacy mean" for each respondent. Missing values for individual self-efficacy items were replaced with the aggregate mean for that item. As only eight values out of a possible total 1,606 were missing, the method was considered appropriate (Mertler \& Vannatta, 2002). The overall self-efficacy score was used for multiple regression analysis.

For multiple regression analysis, the three education items regarding coursework, fieldwork, and overall social work education preparation (field and course work combined) were blended to form a new variable, "academic preparation." Each of the three items comprising this new variable was highly correlated with one another. Together they created a multi-item scale with a Chronbach's Alpha of .78. The creation of this new variable reduced the overall number of personal factors from six to four items, thus creating a more parsimonious model. All variables were entered at the same time to allow the investigator to assess the relative contribution of each item to the total model.

\section{FINDINGS}

The surveys were returned from all areas of the state. The proportion of returns from each region of the state was approximately the same proportion as the total sample. Out of 987 deliverable surveys, 172 were returned. However, 26 returns were excluded from analysis due to lack of a social work degree and/or incomplete answers, leaving 146 usable surveys. Despite a 15\% return rate, the sample size of 146, setting al pha at .05 and using the R-squared effect size of .60, set statistical power for this analysis at more than .95.

All respondents $(\mathrm{N}=146)$ had at least one degree in social work and were licensed as social workers in their state. The majority of respondents were European American (69\%, $n=101$ ), women (84.6\%, $n=121$ ) holding M SW degrees $(79.5 \%, n=116)$. Respondents had a range of less than one year of experience to 52 years of experience since graduation with their highest social work degree. Nearly three-quarters of respondents $(73.3 \%, n=107)$ indicated that they worked in $a$ direct practice role, with a majority of respondents $(60.3 \%, n=88)$ providing services to adults.

Respondents worked in diverse fields of practice including agency-based adult mental health $(17.2 \%, n=25)$, private clinical practice $(10.3 \% n=15)$, child and adolescent services $(17.1 \%, n=25)$, child welfare $(11.6 \%, n=17)$, medical social 
work and services to persons with disabilities (19.1\%, $\mathrm{n}=28)$, general adult services $(9.7 \%, n=14)$, family services $(8.9 \%, n=13)$, and domestic and sexual violence programs $(3.4 \%, \mathrm{n}=5)$.

Self-Efficacy: Respondents had an aggregate self-efficacy mean of 3.59 (SD=87) for all items combined. Table 1 (Self-Efficacy Means \& Standard Deviations in Descending Order) displays each of the 11 items.

\begin{tabular}{|c|c|c|}
\hline Item & Mean & SD \\
\hline Comfort in discussing domestic violence & 4.21 & .86 \\
\hline Capability for identifying domestic violence victims & 3.85 & .84 \\
\hline $\begin{array}{l}\text { Ability to identify domestic violence as an } \\
\text { underlying cause of client problems }\end{array}$ & 3.82 & .93 \\
\hline $\begin{array}{l}\text { Have necessary skills to discuss domestic violence } \\
\text { with clients }\end{array}$ & 3.82 & .99 \\
\hline $\begin{array}{l}\text { Ability to work with clients who are survivors of } \\
\text { past domestic violence }\end{array}$ & 3.79 & 1.04 \\
\hline $\begin{array}{l}\text { Capable of helping battered women develop } \\
\text { safety plans }\end{array}$ & 3.61 & 1.17 \\
\hline $\begin{array}{l}\text { Ability to work with clients who are currently } \\
\text { being abused }\end{array}$ & 3.60 & 1.09 \\
\hline $\begin{array}{l}\text { Capable of assessing the level of danger that a } \\
\text { a battered woman is currently facing }\end{array}$ & 3.34 & 1.13 \\
\hline Capable of assisting clients in same sex relationships & 3.19 & 1.19 \\
\hline $\begin{array}{l}\text { Capable of conducting culturally sensitive } \\
\text { assessments of battered women }\end{array}$ & 3.17 & 1.08 \\
\hline $\begin{array}{l}\text { Capable of discussing legal options available to } \\
\text { battered women }\end{array}$ & 3.03 & 1.19 \\
\hline
\end{tabular}

Professional Experience: Respondents' professional experience varied, with 92\% having contact with battered women in their professional role and only 12 respondents reporting no experience working with battered women. Social workers in all practice settings had professional experience with battered women.

Personal Experience: The majority of respondents $56.5 \%(n=82)$ reported having personal experience with domestic violence, ranging from a little to a great deal. Less than half of the respondents $42.5 \%(n=62)$ were not personally affected by domestic violence.

Academic Preparation: More than half of all respondents $(56 \%, n=81)$ recounted little to no social work coursework specifically addressing domestic violence identification, assessment, and intervention. Only $25 \%$ of all respondents felt that their field placement experiences moderately prepared them to deal with working with battered women. With regard to their overall social work education, more than half $(56 \%)$ reported little to no preparation in working with battered women. 
Continuing Education: More than half of all respondents (56\%) had none to three hours or less of training on this topic, with $30 \%(n=44)$ receiving no training and $26 \%$ ( $n=37$ ) receiving three hours or less.

Table 2 presents the means, standard deviations, and correlations among all of the variables.

\begin{tabular}{|c|c|c|c|c|c|}
\hline Variable & 1 & 2 & 3 & 4 & 5 \\
\hline \multicolumn{6}{|l|}{$\begin{array}{l}\text { 1. DV Practice } \\
\text { Self-Efficacy }\end{array}$} \\
\hline $\begin{array}{l}\text { 2. Professional } \\
\text { Experience }\end{array}$ & $.73^{\text {** }}$ & & & & \\
\hline $\begin{array}{l}\text { 3. Academic } \\
\text { Preparation }\end{array}$ & $.52^{* *}$ & $.41^{* *}$ & & & \\
\hline $\begin{array}{l}\text { 4. Personal } \\
\text { Experience }\end{array}$ & $.19 *$ & $.25^{* *}$ & .15 & & \\
\hline $\begin{array}{l}\text { 5. Continuing } \\
\text { Education }\end{array}$ & $.36^{* *}$ & $.41^{* *}$ & $.28^{* *}$ & $.23^{* *}$ & \\
\hline Mean & 3.59 & 3.12 & 2.39 & 2.22 & 2.43 \\
\hline $\begin{array}{l}\text { Standard } \\
\text { Deviation }\end{array}$ & .87 & 3.12 & .91 & 1.38 & 1.30 \\
\hline
\end{tabular}

Table 3 (Multiple Regression Analysis of Personal Factors on Domestic Violence Practice Self-Efficacy) shows the contributions of each individual personal factor. Together, personal factors accounted for nearly $59 \%$ of the variance (R Squared $=59$ ). Of the four personal factors, only professional experience and academic preparation significantly contributed to the model, with professional experience accounting for nearly $61 \%$ of the total variance explained. Academic preparation accounted for nearly $26 \%$ of the total variance explained. Neither domestic violence training nor personal experiences are significant contributors, with personal experience showing a slightly negative but non-significant relationship.

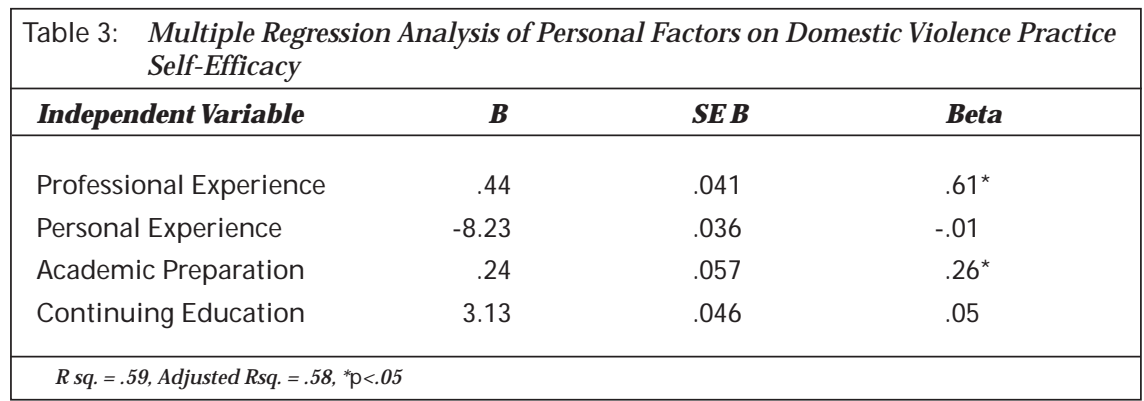




\section{DISCUSSION}

This study identified the personal factors that act as facilitators or barriers experienced by social work practitioners to domestic violence practice self-efficacy. Findings confirm that professional experience is a facilitating factor, and a lack of professional experience is a significant barrier to self-efficacy in this domain. As the strongest determinant of self-efficacy is performance or mastery experiences, the mean of this sample $(M=3.59)$ reflects the findings that nearly $92 \%$ of respondents had professional contact with battered women. High contact with battered women is consistent with previous studies that found that social workers werethe most likely professional group to be contacted (Hamilton \& Coates, 1993) and that battered women have multiple service needs, requiring interaction with as many as 10 different societal institutions (Peled \& Edleson, 1994). These findings are also consistent with other self-efficacy studies that show positive relationships between self-efficacy and professional experience (Holden, et al., 1999; Holden, et al., 1996). These findings are also consistent with previous studies linking professional experience with social work response (Davis \& Carlson, 1986; Tilden, et al., 1994).

Since the personal experience of being battered or watching a member of your family battered is not the same type of performance, mastery, or vicarious learning experiences that serve as strong determinants of self-efficacy, this study fails to determine whether personal experience is a facilitating factor or a barrier to domestic violence practice self-efficacy.

Academic preparation is also a facilitating factor to self-efficacy, and a lack of social work education is a barrier to self-efficacy. Despite the relative importance of academic preparation to self-efficacy, $55 \%$ of all respondents identified little or no coursework specifically addressing domestic violence, $66 \%$ had little or no field experience, and $56 \%$ had little or no overall social work education preparation. As a substitute measure for knowledge, these findings are also consistent with Davis and Carlson (1996).

Specific continuing education training in domestic violence can also be considered a facilitating factor, but the lack of training may not necessarily be a barrier to self-efficacy. Although higher levels of continuing education were associated with higher levels of domestic violence social work self-efficacy, when controlling for all other factors, training was not significantly associated and only accounted for $5 \%$ of the variance explained. A contributing factor to this finding may bethat most respondents (56\%) had none or three hours or less of specific domestic violence training in the past two years. It may be possible that respondents had training previous to this time frame. Additionally, nothing is known about the extent of the training, its content, or how the training was delivered.

This study was exploratory in nature and used a non-experimental survey design based on self-reports from licensed social workers. As such, it holds all of the limitations of non-experimental research (Kerlinger, 1986). Mailed surveys, in particular, are hampered by the inability to check responses given, lack of depth of information generated, and inability to generalize from response rates commonly as low as less than $40 \%$ of the total sample (Fowler, 1993). Certainly that 
was true of this survey; although responses were geographically representative of the state surveyed, a 15\% return rate limits generalizability only to survey respondents. It may also be argued that the survey appealed to social workers with experience with domestic violence.

\section{IMPLICATIONS FOR SOCIAL WORK EDUCATION, PRACTICE, AND RESEARCH}

There are a number of implications for social work education, practice, and research that result from these findings. Academic preparation does make a difference and has more impact on self-efficacy than continuing education and, yet, there is a disconnect between what is taught or not taught in schools of social work and social workers' ubiquitous professional contact with battered women. A recent editorial in the Journal of Social Work Education challenges social work education to develop a comprehensive agenda to "ensure that we prepare competent and effective professionals with beginning knowledge, skills, and attitudes to address domestic abuse in a safe, culturally competent manner" (Danis \& Lockhart, 2003, p. 220). The infusion of domestic violence content into foundation courses should be a primary goal of this agenda. To maximize self-efficacy, the content should be accompanied by opportunities for experiential exercises, particularly in universal screening, risk assessment, and intervention, including safety planning. Domestic violence self-efficacy can be tested before and after specific courses to test the effectiveness of course content and assignments in raising self-efficacy of social work students. Schools of social work can also increase opportunities for students to practice domestic violence related skills in child welfare, hospital emergency rooms, child and family counseling services, school, and substance abuse field settings.

The findings related to personal experience call for a number of considerations. Many social workers may have been exposed to parental violence as a child, involved in past or current abusive relationships themselves, or have been affected by domestic violence vicariously through friends, neighbors, and family members. Supervisors need to offer opportunities for staff to discuss their own personal exposure. This discussion may lead to consciousness-raising among staff about the nature of domestic violence and help to reduce the self-blame that many battered women feel (Levy, 1995). Employee assistance programs also have a responsibility to develop their capacity to respond to employees. Social work educators must also pay attention to the personal experiences of social work students. Research into social workers' personal experience of domestic violence is fundamentally important. Studies can be undertaken to learn more about the nature, intensity, severity, and duration (length of time, when it occurred) of social workers' personal exposure to domestic violence. An important issue to undercover is resolution of the violence (if any) and the role the social worker assigned to herself in escaping the violence. Will social workers who felt they were empowered to escape violence have higher levels of domestic violence practice self-efficacy compared to social workers who felt they did not have an active, effective role in escaping the violence? The impact of secondary victimization or compassion fatigue (Figley, 1995) on social workers who have been battered by intimate partners is an additional research area. Are social workers who have 
al ready been personally affected by domestic violence more or less susceptible to secondary victimization in their practice with battered women?

Despitethe relatively weak contribution of training to overall self-efficacy, training is the modality or intervention most often used to enhance the capacity of providers to respond to specific problems, new situations, and new technologies. Training is considered so important that many licensed social workers must demonstrate that they have received a minimal level of additional training in order to renew their professional licenses each year. In the state of Florida, social workers must receive one hour of domestic violence training to renew their licenses. Are there differences between domestic violence practice self-efficacy between social workers who are required to receive additional training in domestic violence and social workers in states that do not have such a requirement? And what difference does this training make to their clients?

Finally, given the study's limitations with regards to generalizability, this research should be replicated with an emphasis on increasing response rates and expanding the sample to include a more nationally representative sample of professional social workers.

\section{CONCLUSION}

Over the past 20 years, social workers have begun to improve their knowledge of domestic violence and their ability to respond appropriately to survivors of domestic abuse. Social workers have overall positive perceptions of the extent to which they are capable of addressing domestic violence. Personal factors such as professional experience, academic preparation, and continuing education training can facilitate domestic violence practice self-efficacy. Barriers to self-efficacy include a lack of professional experience and inadequate academic preparation. The findings from this study do not confirm whether personal experience is a facilitating factor or a barrier.

Implications for social work education, practice, and research recommended by this study's findings include more emphasis on preparing future social workers for the realities of their practice experiences by increasing specific course content and field experiences for students. The high percentage of social workers who have been personally affected by domestic violence suggests that social work educators and supervisors need to be sensitive to the needs of these workers and students. It is hoped that this study provides a baseline for future research regarding social work response to domestic violence and domestic violence practice self-efficacy.

\section{References}

Abusabha, R., \& Achterberg, C. (1997). Review of self-efficacy and locus of control for nutrition and health related behavior. Journal of theAmerican Dietetic Association, 97(10), 1122-1132.

Ball, M. (1977). Issues of violence in family casework. Social Casework, 58(1), 3-12.

Bandura, A. (1986). The explanatory and predictive scope of self-efficacy theory. Journal of Social and Clinical Psychology, 4(3), 359-373. 
Bandura, A. (1994). Self-efficacy. In H.S. Friedman (Ed.), Encyclopedia of Mental Health (Vol. 3, pp. 421432). San Diego: Academy Press.

Bandura, A. (1997). Self-efficacy: The exercise of control. USA: W.H. Freeman and Company.

Bass, D., \& Rice, J. (1979). Agency responses to the abused wife. Social Casework, 60, 338-342.

Bennett, L.W. (1995). Substance abuse and the domestic assault of women. Social Work 40(6), 760-772.

Bowker, L.H. (1983). Beating wife beating. Lexington: Lexington Books.

Browne, A., \& Bassuk, S. (1997). Intimate violence in the lives of homeless and poor housed women: Prevalence and patterns in an ethnically diverse sample. American Journal of Orthopsychiatry, 67, 261277.

Danis, F.S., \& Lockhart, L. (2003). Domestic violence and social work education: What do we know, what do we need to know? Journal of Social Work Education, 39(2), 215-224.

Davis, L.V. (1984). Beliefs of service providers about abused women and abusing men. Social Work, 29(3), 243-250.

Davis, L.V., \& Carlson, B.E. (1981). Attitudes of service providers toward domestic violence. Social Work Research and Abstracts, 26(4), 34-39.

Davis, L.V., \& Carlson, B.E. (1986). School Personnel's awareness of spouse abuse among parents. Social Work in Education, 8(3), 175-186.

Dobash, R.E., \& Dobash, R. (1979). Violenceagainst wives: A caseagainst thepatriarchy. New York: The Free Press.

Edleson, J.L. (1999). The overlap between child maltreatment and woman battering. Violence Against Women, 5(2), 134-154.

Eisikovits, Z., \& Buchbinder, E. (1996). Pathways to disenchantment: Battered women's views of their social workers. Journal of Interpersonal Violence, 11(3), 425-440.

Figley, C.R. (1995). Compassion fatigue: Secondary traumatic stress disorders from treating thetraumatized. New York: Brunner/Mazel.

Fowler, F.J. (1993). Survey research methods ( $2^{\text {nd }}$ Edition ed.). Newbury Park: Sage Publications, Inc.

Hamilton, B., \& Coates, J. (1993). Perceived helpfulness and use of professional services by abused women. Journal of FamilyViolence, 8(4), 313-324.

Hansen, M., Harway, M., \& Cervantes, N. (1991). Therapists' perception of severity in cases of family violence. Violenceand Victims, 6(3), 225-235.

Holden, G. (1991). The relationship of self-efficacy appraisals to subsequent health related outcomes: A Meta Analysis. Social Work in Health Care, 16(1), 53-93.

Holden, G., Barker, K., Meenaghan, T., \& Rosenberg, G. (1999). Research self-efficacy: A new possibility for educational outcomes assessment. Journal of Social Work Education, 35(3), 463-476.

Holden, G., Cuzzi, L., Spitzer, W., Rutter, D., Rosenburg, G., \& Chernack, P. (1996). The hospital social work self-efficacy scale: Initial development. Research on Social Work Practice, 6(3), 353-365.

Holden, G., Meenaghan, T.J .A., \& Metrey, G. (2002). Outcomes of social work education: The case for social work self-efficacy. Journal of Social Work Education, 38(1), 115-133.

Kerlinger, F.N. (1986). Foundations of behavioral research. (3rd ed.). Orlando: Holt, Rinehart and Winston, Inc.

Levy, B. (1995). Violence against women. In N.V.D. Bergh (Ed.), Feminist practice in the $21^{\text {st }}$ century. Washington, D.C.: NASW Press.

Maddux, J.E. (1995). Self-efficacy, adaptation, and adjustment: Theory, research, and application. New York: Plenum Press.

Mertler, C., \& Vannatta, R.A. (2002). Advanced and multivariate statistical methods, $2^{\text {nd }}$ edition. Los Angeles: Pyrczak Publishing.

Pagelow, M.D. (1981). Woman-battering: Victims and their experiences. Beverly Hills: Sage Publications, Inc. 
Peled, E., \& Edleson, J.L. (1994). Advocacy for battered women: A national survey. Journal of Family Violence, 9(3), 285-296.

Rand, M.R. (1997). Violence related injuries treated in hospital emergency departments. Washington, D.C.: U.S. Department of Justice.

Raphael, J., \& Tolman, R.M. (1997). Trapped by poverty, trapped by abuse: New evidence documenting the relationship between domestic violenceand welfare Chicago: Project for Research on Welfare, Work, and Domestic Violence, Taylor Institute and University of Michigan Research Development Center on Poverty, Risk, and Mental Health.

Ross, M., \& Glisson, C. (1991). Bias in social work intervention with battered women. Journal of Social Service Research, 14(3-4), 79-105.

Tilden, V.P., Schmidt, T.A., Limandri, B.J., Chiodo, G.T., Garland, M.J., \& Loveless, P.A. (1994). Factors that influence clinicians' assessment and management of family violence. American Journal of Public Health, 84(4), 628-634.

Tjaden, P., \& Thoennes, N. (1998). Prevalence, incidence, and consequences of violence against women: Findings from the national violence against women survey. Washington, D.C.: National Institute for Justice and Centers for Disease Control and Prevention.

\section{Author's Note:}

Address correspondence to: Fran Danis, Ph.D., School of Social Work, 720 Clark Hall, University of Missouri, Columbia, Missouri 65211, USA. .E-mail: danisf@missouri.edu 